\title{
EXPLORING THE BENEFITS OF USING STOCK CHARACTERISTICS IN OPTIMAL PORTFOLIO STRATEGIES
}

\author{
Jonathan Fletcher \\ University of Strathclyde
}

Key words: Characteristics, Modelling Portfolio Weights, Mean-Variance Strategies

JEL classification: G10, G11

Current draft: March 2015

Helpful comments received from two anonymous reviewers. I am grateful for use of the Matlab code of Olivier Ledoit and Michael Wolf at http://www.econ.uzh.ch/faculty/wolf/publications.html\#9

Address correspondence to Professor J. Fletcher, Department of Accounting and Finance, University of Strathclyde, Curran Building, 100 Cathedral Street, Glasgow, G4 0LN, United Kingdom, phone: +44 (0) 141548 4963, fax: +44 (0) 552 3547, email: j.fletcher@strath.ac.uk 


\title{
EXPLORING THE BENEFITS OF USING STOCK CHARACTERISTICS IN OPTIMAL PORTFOLIO STRATEGIES
}

\begin{abstract}
I examine the benefits of using stock characteristics to model optimal portfolio weights in stock selection strategies using the characteristic portfolio approach of Brandt, Santa-Clara and Valkanov(2009). I find that there are significant out-of-sample performance benefits in using characteristics in stock selection strategies even after adjusting for trading costs, when investors can invest in the largest 350 U.K. stocks. Imposing short selling restrictions on the characteristic portfolio strategy leads to more consistent performance. The performance benefits are concentrated in the earlier part of the sample period and have disappeared in recent years. I find that there no performance benefits in using stock characteristics when using random subsets of the largest 350 stocks.
\end{abstract}




\section{Introduction}

A number of studies during the past forty years find that stock characteristics such as size (Banz(1981)), book-to-market (BM) ratio (Fama and French(1992)), and momentum (Jegadeesh and Titman(1993)) among others have a significant relation with cross-sectional stock returns even after adjusting for systematic risk $^{1}$. A recent study by Brandt, Santa-Clara and Valkanov(2009) develop a framework to use stock characteristics to model the optimal weights for large scale portfolio optimization, although it can also be used in asset allocation strategies. Brandt et al model the weights of the optimal portfolio as a linear function of a small number of stock characteristics in an expected utility optimization framework.

I use the characteristic portfolio approach of Brandt et al(2009) to examine the benefits of using stock characteristics to model optimal portfolio weights from a U.K. perspective. I use as the investment universe the largest 350 stocks who meet the criteria for inclusion to reflect the relevant universe for U.K. institutional investors following Gregory, Tharyan and Christidis(2013). My study adopts a U.K. perspective as it is one of the largest stock markets in the world and there are a large number of funds that adopt a U.K. equity investment objective. As at December 2014, the total assets under management for U.K. equity open-end mutual funds is $£ 226,275 \mathrm{~m}$ (Investment Management Association).

My study addresses four main research questions. First, I examine whether the unconstrained (Char) and constrained (where there is no short selling, CharSS) characteristic portfolio strategies of Brandt et al(2009) provide significant superior performance after adjusting for trading costs. I use the size, book-to-market (BM), and momentum

\footnotetext{
${ }^{1}$ Excellent surveys of the role of stock characteristics in cross-sectional stock returns includes Subrahmanyam(2010), Cochrane(2011), Goyal(2012), and Nagel(2013). See also the recent studies by Green, Hand and Zhang(2014), Harvey, Liu and Zhu(2015), and McLean and Pontiff(2015).
} 
characteristics. I evaluate the performance of the strategies using the Sharpe(1966) measure, the Certainty Equivalent Return (CER) measure, and the performance fee of Kirby and

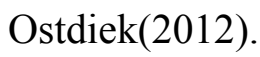

Second, I examine whether the Char and CharSS strategies can outperform both passive benchmarks and alternative mean-variance strategies after adjusting for trading costs. The passive benchmarks include the $1 / \mathrm{N}$ strategy, and a value weighted strategy. The alternative mean-variance strategies include the no short sales constrained sample meanvariance portfolio, the global minimum variance (GMV) portfolio, a no short sales constrained mean-variance portfolio where expected excess returns are estimated using a linear model of stock characteristics, and the volatility timing (VT) strategy of Kirby and Ostdiek(2012). Third, I examine whether the performance of the characteristic portfolio strategies varies across different subperiods. I examine this issue as evidence in Chordia, Subrahmanyam and Tong(2014) and Lewellen(2014) show that the predictive ability of stock characteristics has weakened in recent years in U.S. stock returns. Fourth, I examine the relation between the number of securities in the portfolios and performance where the investment universe each month is a randomly selected subset of stocks from among the largest 350 stocks.

My study provides new evidence of the benefits of using stock characteristics to model the optimal portfolio weights in different applications rather than in U.S. stock returns such as Brandt et al(2009), DeMiguel et al(2013a), and Lamoureux and Zhang(2014). I extend this literature by examining the relation between the number of stocks in the optimal portfolios and performance. I extend the prior U.K. literature of large scale portfolio optimization such as Board and Sutcliffe(1994) and Fletcher(2009) by considering the benefits of using stock characteristics in optimal trading strategies in U.K. stock returns. 
There are three main findings from my study. First, there are significant performance benefits in using stock characteristics to model optimal weights compared to the passive benchmarks and alternative mean-variance strategies when the investment universe contains the largest 350 stocks, even after adjusting for trading costs. The CharSS strategy has the most consistent performance. Second, the superior performance of the Char and CharSS strategies is concentrated in the earlier part of the sample period and disappears in recent years. Third, there is a positive relation between the number of securities in the optimal portfolios and performance when using randomly selected subsets of the investment universe. However the performance of the Char and CharSS strategies is poor relative to the complete investment universe. My findings suggest that using stock characteristics to model portfolio weights is useful when the investment universe contains a large number of individual stocks.

My paper is organized as follows. Section 2 describes the research method. Section 3 provides details on the data used in my study. Section 4 discusses the empirical results. The final section concludes.

\section{Research Method}

\subsection{Literature Review of the Characteristic Portfolio Approach}

The central problem in practical applications of mean-variance analysis is the estimation risk problem (Jobson and Korkie $(1980,1981)$ and Michaud(1989)) in that the true expected returns and covariance matrix are unknown and must be estimated from the data. By modelling the optimal portfolio weights as a function of a small set of stock characteristics, Brandt et al(2009) mitigate the estimation risk problem as only a small number of parameters require to be estimated. The approach can be used regardless how big the investment universe is ${ }^{2}$. The characteristic portfolio approach avoids the modelling of the

\footnotetext{
${ }^{2}$ Plazzi, Torous and Valkanov(2011) adopt this approach in portfolio strategies using commercial real estate.
} 
joint distribution of returns and characteristics, and the stock characteristics can predict both the expected returns and or/covariance matrix when using it in a mean-variance strategy. Hjalmarsson and Manchev(2012) extend the analysis of Brandt et al and derive closed-form solutions of the optimal weights of zero-cost portfolios and apply it to international asset allocation strategies.

Studies by Brandt et al(2009) and Zhang(2012a,b) show that the characteristic portfolio approach performs well in large scale stock selection strategies in U.S. stock returns using size, BM, and momentum characteristics. DeMiguel, Plyakha, Uppal and Vilkov(2013a) find significant performance benefits in using option implied characteristics in the characteristic portfolio approach with short selling constraints. A recent study by Lamoureux and Zhang(2014) use the characteristic portfolio using a broader range of characteristics than in Brandt et al. They find when using all stock characteristics, that the strategy can generate large significant positive alphas relative to the Carhart(1997) model and a high Sharpe performance but delivers large negative performance using the Certainty Equivalent Return (CER) measure.

\subsection{Portfolio Strategies}

Table 1 lists the portfolio strategies considered in my study. The first two strategies (Char and CharSS) are based on Brandt et al(2009). In the Brandt et al approach, the goal of the investor is to choose the portfolio weights $x_{i t}(i=1, \ldots, N)$ for $\mathrm{N}$ risky assets at time $t$ to solve the following expected utility maximization problem:

$$
\operatorname{Max} E_{t}\left[u\left(R_{p t+1}\right)\right]
$$

where $u\left(R_{p t+1}\right)$ is the utility function of the portfolio return at time $t+1$. The investor chooses the optimal portfolio to maximize the expected utility of the portfolio return conditional on the information available at time t. 
To reduce the number of inputs required in estimating optimal portfolios and the corresponding estimation risk, Brandt et al(2009) assume that the optimal portfolio weights are a linear function of a small set of $\mathrm{K}$ security characteristics ${ }^{3}$ given by:

$$
\mathrm{x}_{\mathrm{it}}=\mathrm{x}_{\mathrm{ibt}}+\left(1 / \mathrm{N}_{\mathrm{t}}\right) \theta^{\prime} \mathrm{y}_{\mathrm{it}} \quad \text { for } \mathrm{i}=1, \ldots, \mathrm{N}_{\mathrm{t}}
$$

where $\mathrm{N}_{\mathrm{t}}$ is the number of stocks in the portfolio at time $\mathrm{t}, \mathrm{x}_{\mathrm{ibt}}$ is the weight of stock $\mathrm{i}$ at time $\mathrm{t}$ in a specified benchmark portfolio $b$ of the $\mathrm{N}_{\mathrm{t}}$ stocks, $\theta$ is a $(\mathrm{K}, 1)$ vector of coefficients in the portfolio weight function, and $\mathrm{y}_{\mathrm{it}}$ is a $(\mathrm{K}, 1)$ vector of security characteristics of stock $\mathrm{i}$ at time t. The security characteristics are cross-sectionally standardized to have a zero mean and unit standard deviation. Brandt et al point out that the standardization implies that the crosssectional distribution of $y_{i t}$ will be stationary over time and allows the number of stocks in the optimal portfolio to vary over time.

The $\theta^{\prime} y_{\text {it }}$ term in equation (2) captures the deviations of the optimal portfolio weight of asset $\mathrm{i}$ from the benchmark portfolio weight. I use the value weighted (VW) portfolio of the $\mathrm{N}_{\mathrm{t}}$ assets as the benchmark. The standardization of the characteristics implies that the average of $\theta^{\prime} y_{i t}$ across the $N_{t}$ assets is zero. This fact implies that the deviation of the optimal portfolio weight from the benchmark is a zero-cost portfolio whose weights sum to zero.

Brandt et al(2009) point out the constant coefficients in the portfolio weight function implies that the coefficients that maximize the conditional expected utility in equation (1) will be the same for all dates. This result implies that the same coefficients will maximize the unconditional expected utility of the investor. In this study, I use a mean-variance objective function to implement the characteristic portfolio approach of Brandt et al(2009). I use the mean-variance approach to make it comparable to the alternative mean-variance strategies used in this study. Using excess returns the investor searches for $\theta$ to:

\footnotetext{
${ }^{3}$ The modelling of portfolio weights is linked to earlier work by Brandt(1999), Ait-Sahalia and Brandt(2001), and Brandt and Santa-Clara(2006).
} 


$$
\begin{array}{r}
\operatorname{Max} E\left(\mathrm{r}_{\mathrm{pt}+1}\right)-(\gamma / 2) \operatorname{var}\left(\mathrm{r}_{\mathrm{pt}+1}\right) \\
\mathrm{r}_{\mathrm{pt}+1}=\sum_{\mathrm{i}=1}{ }^{\mathrm{Nt}}\left(\mathrm{x}_{\mathrm{ibt}}+\left(1 / \mathrm{N}_{\mathrm{t}}\right) \theta^{\prime} \mathrm{y}_{\mathrm{it}}\right) \mathrm{r}_{\mathrm{it}+1}
\end{array}
$$

where $r_{p t+1}$ is the excess return of the optimal portfolio at time $t+1, r_{i t+1}$ is the excess return of asset $i$ at time $t+1$, and $\gamma$ is the level of risk aversion. I estimate $\theta$ for the Char strategy by solving the sample analogue of (3).

The CharSS strategy uses the characteristic portfolio approach but imposes no short selling restrictions. I use the approach of Brandt et al(2009) by truncating the weights as:

$$
\mathrm{X}_{\mathrm{it}}=\max \left(0, \mathrm{x}_{\mathrm{it}}\right) / \Sigma_{\mathrm{i}=1}^{\mathrm{Nt}}\left(\max \left(0, \mathrm{x}_{\mathrm{it}}\right)\right)
$$

The restriction in (5) ensures the optimal portfolio weights are non-negative and sum to one.

I compare the performance of the Char and CharSS strategies to two passive benchmarks and four alternative mean-variance strategies, which are listed in Table 1 . The passive benchmarks include the $1 / \mathrm{N}$ strategy where an equal weight is invested in each of the $\mathrm{N}_{\mathrm{t}}$ assets (DeMiguel, Garlappi and Uppal(2009)) and the value weighted (VW) portfolio of the $\mathrm{N}_{\mathrm{t}}$ assets. The first alternative mean-variance strategy is a no short sales constrained mean-variance portfolio, where expected excess returns are estimated by a linear characteristic model as in Lewellen(2014) (see Appendix) and the covariance matrix is estimated using the Ledoit and Wolf(2004) shrinkage covariance matrix. The second alternative mean-variance strategy is the GMV portfolio with the Ledoit and Wolf shrinkage covariance matrix. The third alternative mean-variance strategy is the no short sales constrained sample mean-variance portfolio. The final strategy is the VT strategy of Kirby and Ostdiek(2012) (see Appendix) using the shrinkage covariance matrix of Ledoit and Wolf.

I use the Sample strategy as this is the baseline mean-variance strategy which uses sample moments. I impose short selling restrictions here as the sample covariance matrix is singular when $\mathrm{N}>\mathrm{T}$. I use the MVChar strategy to compare how well the Char and CharSS strategies perform relative to a mean-variance model where stock characteristics are used to 
model expected excess returns as in Haugen and Baker(1996) rather than to model optimal portfolio weights. I select the GMV portfolio using the Ledoit and Wolf(2004) shrinkage covariance matrix as it performs well in the recent study by DeMiguel, Martin-Utrera and Nogales $(2013 b)^{4}$. I do not consider any other approaches that either shrink the return moments or use shrinkage portfolio strategies, as DeMiguel et al find in their 100 stock universe that the GMV portfolio using the shrinkage covariance matrix of Ledoit and Wolf has the second highest after-cost Sharpe(1966) performance and no other strategy provides a significant higher Sharpe performance. I consider the VT strategy as Kirby and Ostdiek(2012) find that it performs well in domestic U.S. asset allocation strategies (see also Fletcher(2011)). For all the mean-variance strategies, I use a risk aversion level of 5 and for the VT strategy I use a tuning parameter of 2.

\section{Table 1 here}

\subsection{Evaluating Out-of-Sample Performance of the Strategies}

I evaluate the out-of-sample performance of the strategies using a similar approach to DeMiguel et al(2009) and Kirby and Ostdiek(2012) using a monthly portfolio formation. At the start of each evaluation month between July 1991 and December 2012, I estimate the optimal weights of each strategy using a rolling estimation window of 120 months. Given the optimal weights, I then estimate the excess portfolio return for each strategy during the evaluation month.

\footnotetext{
${ }^{4}$ Ledoit and Wolf(2014) propose a nonlinear shrinkage covariance matrix. They find that the GMV portfolio using this approach performs better than the linear shrinkage covariance matrix. I do not consider the nonlinear shrinkage covariance matrix here but is an interesting issue for future research.
} 
For each evaluation month, I use the largest 350 stocks at the end of the estimation window that meet the criteria for inclusion. I only select companies with continuous return observations during the estimation window and characteristic data at the start of the evaluation month. I do not include foreign companies, secondary shares, and investment trusts ${ }^{5}$. The requirement of continuous returns in the estimation window is similar to Jagannathan and Ma(2003) and DeMiguel et al(2013b). My approach can be followed by investors in real time as I do not require stocks to have an available return in the evaluation month. Where the included stock has a missing return in the evaluation month, I assign a zero return as in Liu and Strong(2008) due to temporary suspension or death. Where the death is deemed valueless using the information in the London Share Price Database (LSPD) provided by London Business School, I assign a $-100 \%$ return as in Dimson, Nagel and Quigley(2003) to correct for the delisting bias of Shumway(1997).

I evaluate the out-of-sample performance of the strategies after adjusting for the impact of turnover and trading costs using a number of performance measures. I estimate turnover as in DeMiguel et al(2009). The turnover is estimated each month as:

$$
\text { Turnover }=\Sigma_{\mathrm{i}=1} \mathrm{~N}\left|\mathrm{x}_{\mathrm{it}+1}-\mathrm{X}_{\mathrm{it}}\right|
$$

where $x_{i t+1}$ is the optimal weight of asset $i$ at time $t+1, x_{i t}$ is the optimal weight of asset $i$ at time $\mathrm{t}$ adjusted for buy and hold returns at time $\mathrm{t}+1$. The turnover measure reflects the fact that the portfolio weights change even without any explicit trading due to the return performance of the assets in the portfolio. I calculate the time-series average turnover for each strategy. I estimate the after-cost portfolio excess returns using a level of proportional costs per transaction of 50 basis points as in DeMiguel et al(2009) and Kirby and

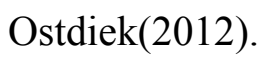

\footnotetext{
${ }^{5}$ Investment trusts are equivalent to U.S. closed-end funds.
} 
I use three performance measures. The first measure is the Sharpe(1966) performance measure and is given by the average portfolio excess return divided by the standard deviation of portfolio excess returns. The second measure is the Certainty Equivalent Return (CER) performance and is given by:

$$
\mathrm{CER}=\mathrm{r}_{\mathrm{p}}-(\gamma / 2) \sigma_{\mathrm{p}}^{2}
$$

where $r_{p}$ is the average excess return of strategy $p$, and $\sigma_{p}^{2}$ is the variance of the excess returns of strategy p. I adapt the $z$-test of Ledoit and $\operatorname{Wolf}(2008)^{6}$ to examine whether the Sharpe and CER measures for every pair of strategies are equal to each other. The third measure is the performance fee ${ }^{7}\left(\Delta_{\gamma}\right)$ of Kirby and Ostdiek(2012) (see also Fleming, Kirby and Ostdiek(2001,2003)). Kirby and Ostdiek interpret the performance fee as the maximum fee that an investor would be willing to pay each period to change from the $1 / \mathrm{N}$ strategy to one of the optimal strategies. I use the one-tail $z$-test to examine the null hypothesis that $\Delta_{\gamma} \leq$ 0 similar to Kirby and Ostdiek(2012). I use a risk aversion level of 5 to estimate the CER performance and performance fee. The test statistics are corrected for the effects of heteroskedasticity and serial correlation using the automatic lag selection (without prewhitening) method of Newey and West(1994).

\section{Data}

I evaluate the performance of the portfolio strategies using individual U.K. stocks. The sample period is between July 1981 and December 2012. The monthly stock returns and market values come from LSPD. LSPD provides monthly return data on all companies

\footnotetext{
${ }^{6}$ Ledoit and Wolf(2008) derive the $z$-test using the delta method. The parameters to calculate the Sharpe measure can be estimated as moment conditions in a generalized method of moments (GMM) (Hansen(1982)) estimation. The delta method is then used to derive the $z$ test that the Sharpe performance measures of two strategies are equal to one another.

${ }^{7}$ Fuller details of the performance fee are included in the Appendix.
} 
quoted on the London Stock Exchange and smaller markets such as the Alternative Investment Market (AIM) since 1975 and so is free of survivorship bias. I use the size, BM, and momentum characteristics, as in Brandt et al(2009) and Zhang(2012a). The characteristics are described in the Appendix. The accounting data used to estimate the BM ratio is collected from Worldscope provided by Thompson Financial. I collect the return on the one-month U.K. Treasury Bill from LSPD and Datastream to calculate excess returns.

Table 2 reports summary statistics of the characteristics and excess returns of the largest 350 companies that meet the criteria for inclusion each month between July 1991 and December 2012. The summary statistics include the time-series averages of the crosssectional mean, median, and standard deviation of the characteristic values at the start of each evaluation month and the evaluation month excess returns. The momentum characteristic and returns are in $\%$ terms and the size and $(1+\mathrm{BM})$ characteristics are in logs.

Table 2 here

Table 2 shows that the time-series average of the mean excess returns is $1.019 \%$ with an average volatility of $9.822 \%$. The average median excess return is considerably lower than the mean. The median size and BM characteristics are close to their mean values. In contrast, the median momentum characteristic is a lot lower than the mean reflecting the greater impact of outliers.

\section{Empirical Results}

\subsection{Performance of Strategies in the Overall Sample Period}

I begin my empirical analysis by considering the performance of the Brandt et al(2009) portfolio strategies. I consider both the Char and CharSS strategies, along with two 
strategies where trading costs are including within the mean-variance objective function ${ }^{8}$, where trading costs are assumed either at 50 basis points $\left(\mathrm{Char}_{50}\right)$ or 10 basis points $\left(\mathrm{Char}_{10}\right)$. Table 3 reports the out-of-sample performance of the four portfolio strategies along with the two benchmark strategies after adjusting for trading costs of 50 basis points. Panel A of the table includes the mean $(\%)$, standard deviation $(\sigma, \%)$, Sharpe measure, CER measure $(\%)$, and the performance fee $(\Delta, \%)$. To conserve space, I do not report the one-tail $z$-test of the performance fee but denote statistical significance.

Panels B and C of Table 3 report the $z$-test of equal Sharpe and CER performance for every pair of strategies. Where the test statistic is positive (negative), the strategy in the row has a higher (lower) Sharpe/CER performance than the strategy in the column. Panel D of the table reports summary statistics of the optimal weights in the four strategies and the two passive benchmarks. The summary statistics includes time-series averages (\%) of the mean absolute weight $(|x|)$, minimum weight $(\operatorname{Min} x)$, maximum weight $(\operatorname{Max} x)$, the sum of the short positions $(\operatorname{Sum}(x<0))$, the proportion of stocks held in short positions ( $\operatorname{Prop}(x<0))$, and held in long positions $(\operatorname{Prop}(\mathrm{x}>0))$. The final column reports the average turnover of each strategy.

Table 3 here

Panel A of Table 3 shows that the Char strategy is characterized by both a high mean excess return and high volatility. When including trading costs in the objective function, there is a drop in the mean and volatility of portfolio excess returns, especially for the Char ${ }_{50}$

\footnotetext{
${ }^{8}$ Including trading costs in the objective function provides a way of mitigating the high turnover of the Char strategy. I thank one of the reviewers for suggesting an examination of this point.
} 
strategy. There is however a much bigger impact on the mean and volatility of portfolio excess returns when short selling restrictions are imposed. The CharSS strategy has volatility close to the $1 / \mathrm{N}$ and VW strategies but a much higher mean excess returns.

All four Char strategies in Table 3 significantly outperform the $1 / \mathrm{N}$ and VW strategies using the Sharpe measure after adjusting for trading costs. The Char strategy has the highest Sharpe performance among the four characteristic portfolio strategies and provides a significant higher Sharpe performance than the $\mathrm{Char}_{50}$ and Char 10 strategies. The Char 10 strategy provides a significant higher Sharpe performance than the Char ${ }_{50}$ strategy. Although the Char, Char 50 , and Char $_{10}$ strategies have good Sharpe performance, they perform poorly using the CER measure and performance fee. The negative performance using the CER measure and performance fee is driven by the high volatility of these strategies, which is penalized by risk aversion. The CharSS strategy is the only strategy with a positive CER performance and a significant positive performance fee. The CharSS strategy provides a significant higher CER performance than the $1 / \mathrm{N}$ strategy but not relative to the other strategies. This result is driven by the high standard errors of the test statistics.

The summary statistics in panel D of Table 3 shows that the Char strategy has a large turnover and a large exposure to short positions. Just over $50 \%$ of the Char strategy is held in short positions with an average sum of $-375.5 \%$, which implies that the average sum of long positions is $475.5 \%$. The average minimum and maximum weights of the Char strategy suggest that there are large positions in some assets. Including trading costs in the objective function as in the $\mathrm{Char}_{50}$ and $\mathrm{Char}_{10}$ strategies reduces the turnover of the Char strategy but it still remains high with a large exposure to short positions. Imposing short selling restrictions as in the CharSS strategy is a much more effective way to reduce turnover in the Char strategy. The CharSS strategy has a turnover less than a $1 / 5^{\text {th }}$ the alternative characteristic 
portfolio strategies. The CharSS strategy has good diversification spread with on average $48 \%$ of stocks held and the weights are not extreme.

Table 3 suggests that the Char strategy does provide significant performance benefits relative to passive benchmarks using the Sharpe measure but performs poorly using the CER measure and performance fee. The CharSS strategy has the most consistent performance across the performance measures and significantly outperforms passive benchmarks. Since including trading costs in the objective function has only a marginal impact on reducing turnover of the Char strategy and has poor CER performance and negative performance fees, I do not proceed with the $\mathrm{Char}_{50}$ and $\mathrm{Char}_{10}$ strategies in the remainder of the paper.

The superior Sharpe performance of the Char and CharSS strategies relative to the passive benchmarks is similar to Brandt et al(2009). DeMiguel et al(2013a) also find that the constrained Brandt et al strategy often provides a significant higher Sharpe performance than the $1 / \mathrm{N}$ strategy using a more frequent portfolio formation than monthly. The high turnover required by the Char strategy is similar to DeMiguel et al. The finding that the performance of the Char strategy can be sensitive to the performance measure used is similar to Lamoureux and Zhang(2014).

I next examine how well the Char and CharSS strategies perform relative to the alternative mean-variance strategies. Table 4 reports the out-of-sample performance of the alternative mean-variance strategies and the corresponding $z$-tests of equal Sharpe and CER performance.

Table 4 here

Panel A of Table 4 shows that none of the alternative mean-variance strategies have a higher Sharpe or CER performance than the CharSS strategy. All of the strategies 
underperform the Char strategy using the Sharpe measure but not using the CER measure. Among the alternative mean-variance strategies, the VT strategy has the best performance with a higher Sharpe and CER performance than the two passive benchmarks. The VT strategy provides a significant performance fee. The MVChar strategy has reasonable Sharpe performance but like the Char strategy has very poor performance using the CER measure and performance fee due to the high volatility of the strategy. Both the GMV and Sample strategies perform poorly in the individual stock universe. Both strategies have a lower Sharpe and CER performance than the passive benchmarks. The GMV strategy does deliver the lowest volatility across all strategies but has a tiny mean excess returns, which leads to the poor performance using the Sharpe and CER measures

Panels $\mathrm{B}$ and $\mathrm{C}$ of Table 4 show that the Char strategy is able to significantly outperform all the alternative mean-variance strategies using the Sharpe measure. The CharSS strategy provides a significant higher Sharpe performance than the GMV and Sample strategies. There are fewer significant differences with the CER measure, again due to high standard errors. The CharSS strategy provides a significant higher CER performance than the Sample strategy and the VT strategy significantly outperforms both the 1/N and Sample strategies.

The summary statistics of the optimal weights in panel D of Table 4 shows that all of the alternative mean-variance strategies have a lower turnover than the Char strategy. Both the MVChar and Sample strategies hold around $50 \%$ of stocks in their portfolios and the average maximum weight is $21.32 \%$ (Sample) and $29.87 \%$ (MVChar). This is much larger than for the CharSS strategy of $3.99 \%$. The GMV strategy holds around $60 \%$ of stocks in long positions but there is a sizeable exposure to short positions with an average sum of $102.86 \%$. The VT strategy has a low turnover, which is even lower than the $1 / \mathrm{N}$ strategy. It includes all stocks and no stocks have extreme weights. 
Tables 3 and 4 suggest that the CharSS strategy performs well relative to the alternative mean-variance strategies and the Char strategy significantly outperforms all strategies using the Sharpe measure. These results highlight the benefits of using stock characteristics to model optimal weights. The superior performance relative to the MVChar strategy suggests that it is better to use characteristics to model optimal weights rather than estimate expected excess returns.

I conduct a number of robustness tests of the findings in Tables 3 and 4 . First, I repeat the tests in Tables 3 and 4 but this time use lower trading costs of 10 basis points. The main impact of lower trading costs is that the negative CER performance of the Char strategy disappears. The Char strategy now has the highest after-cost CER performance across all strategies, albeit the differences are not statistically significant due to high standard errors. Second, I use a rolling estimation window of 60 months. The use of a shorter estimation window has little impact on the results in Tables 3 and 4, except that there is a marginal reduction in the performance of the Char and CharSS strategies. Third, I use an annual portfolio formation rather than the monthly portfolio formation. Using an annual portfolio formation does lead to a substantial reduction in turnover of the Char strategy. However the superior performance of the Char and CharSS strategies disappears. The Char strategy no longer significantly outperforms all the other strategies using the Sharpe measure.

The final robustness test I consider is that I repeat the tests using the largest 100 companies $^{9}$. I find that all of the performance benefits of the Char and CharSS strategies disappear using this investment universe. This result is not driven by including financials in the investment universe as I find similar results when financials are excluded. The difference

\footnotetext{
${ }^{9}$ Gregory et al(2013) point out from informal conversations with fund managers that the largest 100 companies is viewed as the investment universe of U.K. companies for large international investors.
} 
in performance between the two groups of assets is likely due to the weaker predictive relation between excess returns and stock characteristics in the largest companies (Fama and French(2008), Lewellen(2014)). To examine this issue, I estimate the average slope coefficients in the portfolio weight function of the Char strategy from the two investment universes. In the largest 350 companies, the average slope coefficients are -3.027 (Size), $7.428(\mathrm{BM})$, and 8.920 (Momentum). The average slope coefficients on the BM and momentum characteristics are considerably larger compared to the largest 100 companies universe where the average slope coefficients are -5.355 (Size), $2.394(\mathrm{BM})$, and 4.173 (Momentum). This pattern in slope coefficients is consistent with stock characteristics being less beneficial when restricted to the very largest stocks.

\subsection{Subperiod Results}

In this subsection, I examine how the Char and CharSS strategies perform in different subperiods. My main tests focus on the performance of the strategies where the subperiods are defined as before the financial crisis (July 1991 and December 2006) and since that time (January 2007 and December 2012). I also consider a number of alternative ways of splitting the sample period including two equal subperiods, recession and expansion months ${ }^{10}$, and three equal subperiods. Table 5 reports the out-of-sample after-cost performance of the eight strategies between July 1991 and December 2006 (panel A) and January 2007 and December 2012 (panel B). To conserve space, I do not report the $z$-test of equal Sharpe and CER performance between the strategies but is available on request.

Table 5 here

\footnotetext{
${ }^{10}$ In the U.K. a recession is defined as two successive quarters of negative economic growth as measured by real GDP. The recession months are those months from the quarters where the U.K. is officially in a recession.
} 
Table 5 shows that the superior performance of the Char and CharSS strategies are concentrated in the first subperiod. In panel A of Table 5, the Char strategy has the highest Sharpe and CER performance across all strategies but has a negative performance fee. The Char strategy significantly outperforms all strategies using the Sharpe measure except for the CharSS strategy. There is no significant outperformance by the Char strategy using the CER measure due to high standard errors.

Imposing short selling constraints on the Char strategy leads to a sharp drop in both the mean and volatility of the after-cost portfolio excess returns. The CharSS strategy has the second highest Sharpe and CER performance across all strategies and has a significant positive performance fee. The CharSS strategy provides a significant higher Sharpe performance than all the other strategies excluding the Char and MVChar strategies. The CharSS strategy significantly outperforms the 1/N, VW, GMV, and Sample strategies using the CER measure. The VT strategy also has a reasonable positive performance in the first subperiod and provides a significant positive performance fee.

Panel B of Table 5 shows that all of the superior performance of the Char and CharSS strategies disappears in the second subperiod. The Char strategy now underperforms both passive benchmarks with a large negative CER performance and performance fee. This underperformance is driven by the high volatility of the Char strategy. The CharSS strategy underperforms both passive benchmarks using the CER measure and only has a marginally higher Sharpe performance than the passive benchmarks. The MVChar strategy is even more extreme in its' performance in the second subperiod. None of the optimal strategies now significantly outperform the passive benchmarks using either measure.

The subperiod performance results for the Char and CharSS strategies is consistent with the weaker predictive relations of stock characteristics in recent years (Lewellen(2014), 
Chordia et al(2014)). When examining the monthly slope coefficients in the portfolio weight function of the Char strategy, the average slope coefficients on the BM and momentum characteristics are considerably smaller in the second subperiod. The poor performance of the strategies in the second subperiod is driven by the performance of the strategies in the 2007 and 2008 period. All of the strategies perform a lot better in the 2009 and 2012 period. However, the optimal strategies are still unable to outperform the $1 / \mathrm{N}$ strategy in the latter period.

I find similar results if I split the sample period into two equal subperiods. The superior performance of the Char strategy is largely concentrated in the earlier part of the sample period. When I look at the three equal subperiods, the Char strategy significantly outperforms all strategies using the Sharpe measure and all strategies using the CER measure, except the MVChar strategy at the $10 \%$ significance level. The Char strategy also has a significant positive performance fee. In the expansion and recession months, I find similar results to Zhang(2012a). The Char and CharSS strategies perform better in expansion months but perform poorly in recession months.

\subsection{Relation between Number of Securities in Portfolios and Performance}

In this subsection, I examine the impact of the number of securities in the optimal portfolios on the performance of the strategies. To examine this issue, at the start of each evaluation month, I randomly select optimal portfolios of different portfolio size from among the largest 350 stocks. I select $\mathrm{N}=50, \mathrm{~N}=100$, and $\mathrm{N}=200$. Table 6 reports the after-cost performance of the strategies using randomly selected portfolios across the whole sample period.

Table 6 here 
Table 6 shows that there is a positive relation between the number of securities in the optimal portfolios and performance. However the performance of the strategies is poorer than observed in the complete investment universe. At $\mathrm{N}=50$ and 100 , there are only two strategies which have positive mean excess returns. The remaining strategies have negative mean excess returns, which produces a negative Sharpe and CER performance. The two best performing strategies are the CharSS and MVChar strategies. When $\mathrm{N}=50$, both strategies have a small positive Sharpe performance but a large negative CER performance. The performance of both strategies improves when $\mathrm{N}=100$ and the CharSS strategy has a significant positive performance fee.

When $\mathrm{N}=200$, the performance of the strategies tends to improve and most strategies now have a positive Sharpe performance. However the performance is weaker than the performance in Tables 3 and 4. The CharSS strategy has the best Sharpe and CER performance across all strategies and has a significant positive performance fee. The performance results in Table 6 suggest that as the number of securities in the portfolios increases, the after-cost performance of the strategies improves. The negative after-cost performance in Table 6 stems from the use of randomly selected portfolios each month. The use of random portfolios incurs a much higher turnover and so penalizes the after-cost performance of the strategies. When considering the before-cost performance of the strategies, the negative mean excess returns of each strategy disappears and all strategies provide a positive Sharpe performance.

Comparing the before-cost performance of the Char and CharSS strategies of the randomly selected portfolios to the after-cost performance of the Char and CharSS strategies in Table 3 shows that the before-cost performance in the randomly selected portfolios is generally poorer. It is only when $\mathrm{N}=200$, that the before-cost Sharpe performance of the Char strategy is higher than the after-cost performance in Table 3. For the CharSS strategy, 
the before-cost Sharpe performance is higher than the after-cost performance of the CharSS strategy in Table 3 when $\mathrm{N}=100$ and 200. These results suggest that the use of random subsets of the investment universe hurts the performance of the Char and CharSS strategies beyond the impact of turnover. This poorer performance is driven by the weaker predictive ability of stock characteristics among the largest stocks (Fama and French(2008), Lewellen(2014)), which arises when using subsets of the investment universe.

\section{Conclusions}

My study examines the benefits of using stock characteristics to model the optimal weights in stock selection strategies. There are three main findings from my study. First, there are significant performance benefits in using characteristics to model the optimal weights when the investment universe contains the largest 350 U.K. stocks even after adjusting for the impact of trading costs. The Char strategy provides significant superior Sharpe performance and outperforms both passive benchmarks and the alternative meanvariance strategies. This finding is supportive of the characteristic portfolio approach of Brandt et al(2009). However the Char strategy does have poor negative CER performance, which is similar to Lamoureux and Zhang(2014). The negative CER performance of the Char strategy disappears at lower trading costs of 10 basis points. Imposing short selling restrictions on the Char strategy leads to more consistent performance, as the CharSS strategy has both a positive CER performance and a significant positive performance fee. Restricting the investment universe to the largest 100 stocks, the superior performance of the Char and CharSS strategies disappears. This result is due to the weaker predictive ability of stock characteristics in the largest stocks (Fama and French(2008), Lewellen(2014)). This result suggests that the characteristic portfolio approach is less useful to institutional investors restricted to the largest 100 U.K. stocks. 
Second, I find that the superior performance of the Char and CharSS strategies is concentrated in the pre-2007 period and disappears in the second period. For the Char strategy, this superior performance is driven by the earliest part in the sample period. The weakening performance of the Char strategy over time is consistent with the weaker predictive ability of the stock characteristics over time as in Lewellen(2014) and Chordia et al(2014). I also find that the Char and CharSS strategies perform better in expansion periods rather than in recession periods, which is consistent with Zhang(2012a).

Third, I find a positive relation between the number of securities in the portfolio and performance when using randomly selected subsets of the investment universe of the largest 350 U.K. stocks. However the performance of the Char and CharSS strategies is poor relative to the complete investment universe. This result is driven by higher turnover when forming randomly selected portfolios each month and by the fact that stock characteristics have a weaker predictive relations among large stocks (Fama and French(2008), Lewellen(2014).

My results suggest that there are performance benefits in using stock characteristics to model optimal portfolio weights, when investing in the largest 350 U.K. stocks but not subsets of these stocks. My study has focused on this investment universe as most institutional investors concentrate on these stocks (Gregory et al(2013)). It would be of interest to consider the benefits of using stock characteristics in small stock investment universes given the stronger predictive ability of characteristics among smaller stocks. My study only uses three stock characteristics and so the analysis could be extended to use a broader range of stock characteristics such as in Lewellen(2014) or the use of characteristics from option implied information as in DeMiguel et al(2013a). My analysis focuses on a U.K. perspective and it would be of interest to consider the performance benefits of the characteristic portfolio approach in other markets. I leave these issues to future research. 


\section{Appendix}

\section{A) Estimating expected excess returns in MVChar strategy}

The expected excess returns in the MVChar strategy are estimated using the Fama and MacBeth(1973) cross-sectional regressions as in Lewellen(2014). I use a two-step approach. First for each month during the estimation window the following cross-sectional regression is run:

$$
\mathrm{r}_{\mathrm{it}+1}=\mathrm{c}_{\mathrm{ot}+1}+\Sigma_{\mathrm{k}=1} \mathrm{~K}_{\mathrm{kt}+1} \mathrm{Z}_{\mathrm{ikt}}+\mathrm{u}_{\mathrm{it}+1}
$$

where $r_{i t+1}$ is the excess return of asset $i$ at time $t+1, Z_{i k t}$ is the value of the kth characteristic of asset $\mathrm{i}$ at time $\mathrm{t}$ for $\mathrm{k}=1, \ldots, \mathrm{K}$, and $\mathrm{u}_{\mathrm{it}+1}$ is a residual term of asset $\mathrm{i}$ at time $\mathrm{t}+1$. Second, the expected excess returns (v) are then calculated as:

$$
\mathrm{v}=\mathrm{c}_{0}+\mathrm{Zc}_{\mathrm{K}}
$$

where $\mathrm{c}_{0}$ is the time-series average of $\mathrm{c}_{0 \mathrm{t}+1}$ from the estimation window, $\mathrm{Z}$ is a $(\mathrm{N}, \mathrm{K})$ matrix of security characteristics at the start of the evaluation month, and $\mathrm{c}_{\mathrm{K}}$ is a $(\mathrm{K}, 1)$ vector of the time-series averages of $c_{k t+1}$ from the estimation window.

\section{B) VT Strategy}

The optimal weights in the VT strategy for each asset $\left(\mathrm{x}_{\mathrm{i}}\right)$ are given by:

$$
x_{i}=\left(1 / \sigma_{i}^{2}\right)^{\eta} / \Sigma^{N}{ }_{i=1}\left(1 / \sigma_{i}^{2}\right)^{\eta} \quad i=1, \ldots N
$$

where $\sigma^{2}$ is the variance of asset $i$ calculated from the relevant diagonal cell of the Ledoit and Wolf(2004) shrinkage covariance matrix, and $\eta$ is the tuning parameter. The weights in asset i depend upon the variance of asset $i$ relative to the variances of the other assets. The tuning parameter allows the investor to control how aggressive the weights will change in response to the changes in variance.

\section{C) Performance Fee}

The performance fee is the fee (as a fraction of invested wealth) that makes the expected utilities of two alternative strategies equal to one another. The performance fee 
assumes that investors have quadratic utility functions. Define strategy $\mathrm{i}$ as the $1 / \mathrm{N}$ strategy and strategy $\mathrm{j}$ as one of the optimal asset allocation strategies. Kirby and Ostdiek(2012) interpret the performance fee as the maximum fee that an investor would be willing to pay each period to change from strategy $\mathrm{i}$ to strategy $\mathrm{j}$. The performance fee can be calculated as:

$$
\Delta_{\gamma}=-\gamma^{-1}\left[1-\gamma\left(\mathrm{E}\left(\mathrm{R}_{\mathrm{pjt}+1}\right)\right]+\gamma^{-1}\left[\left(\left(1-\gamma \mathrm{E}\left(\mathrm{R}_{\mathrm{pjt}+1}\right)\right)^{2}-2 \gamma \mathrm{E}\left(\mathrm{U}\left(\mathrm{R}_{\mathrm{pit}+1}\right)-\mathrm{U}\left(\mathrm{R}_{\mathrm{pjt}+1}\right)\right)\right]^{1 / 2}\right.\right.
$$

where $\gamma$ is the relative risk aversion level, $\mathrm{E}\left(\mathrm{R}_{\mathrm{pjt}+1}\right)$ is the expected portfolio return of strategy $\mathrm{j}$, and $\mathrm{E}\left[\mathrm{U}\left(\mathrm{R}_{\mathrm{pit}+1}\right)-\mathrm{U}\left(\mathrm{R}_{\mathrm{pjt}+1}\right)\right]$ is the expected difference in utility for a quadratic utility investor between the $1 / \mathrm{N}$ strategy (strategy i) and strategy $\mathrm{j}$.

\section{D) Security Characteristics}

1. Size

The size of the company is given by the monthly market values. I use the log of the monthly market values at the prior month-end to measure size. I set companies with zero market values to missing values.

2. Book-to-Market (BM) ratio

The monthly BM ratio is calculated using the book value of equity at the fiscal yearend (WC03501) during the previous calendar year divided by the prior month-end market value. I set companies with negative book values or zero market values to missing values. I use the $\log$ of one plus the BM ratio.

\section{Momentum}

I calculate the momentum characteristic each month as the prior cumulative returns of the stock between months -12 to -2 . Companies must have continuous return observations during the past 12 months, otherwise the momentum characteristic is set to missing values. 
Table 1 List of Portfolio Strategies

\begin{tabular}{|c|c|c|}
\hline No. & Av & Abbreviation \\
\hline 1 & $\begin{array}{l}\text { Characteristic portfolio strategies } \\
\text { Parametric portfolio of Brandt et al(2009) where portfolio weights } \\
\text { are a linear function of size, BM, and momentum stock } \\
\text { characteristics. Assume risk aversion } \gamma \text { of } 5 \text { and allow short } \\
\text { selling. }\end{array}$ & Char \\
\hline 2 & $\begin{array}{l}\text { Parametric portfolio of Brandt et al(2009) where portfolio weights } \\
\text { are a linear function of size, BM, and momentum stock } \\
\text { characteristics. Assume risk aversion } \gamma \text { of } 5 \text { and no short selling } \\
\text { constraints are imposed. } \\
\text { Passive benchmarks }\end{array}$ & CharSS \\
\hline 3 & Equally-weighted portfolio of the $\mathrm{N}_{\mathrm{t}}$ assets. & $1 / \mathrm{N}$ \\
\hline 4 & $\begin{array}{l}\text { Value-weighted portfolio of the } \mathrm{N}_{\mathrm{t}} \text { assets. } \\
\text { Alternative mean-variance strategies }\end{array}$ & VW \\
\hline 5 & $\begin{array}{l}\text { Mean-variance portfolio with no short sales constraints. Expected } \\
\text { excess returns are a linear function of size, BM, and momentum } \\
\text { stock characteristics and use the shrinkage covariance matrix of } \\
\text { Ledoit and Wolf(2004). Assume risk aversion } \gamma \text { of } 5 \text {. }\end{array}$ & MVChar \\
\hline 6 & $\begin{array}{l}\text { Global minimum variance portfolio using the shrinkage covariance } \\
\text { matrix of Ledoit and Wolf }(2004)\end{array}$ & GMV \\
\hline 7 & $\begin{array}{l}\text { Sample mean-variance portfolio with no short sales constraints. } \\
\text { Assume risk aversion } \gamma \text { of } 5 \text {. }\end{array}$ & Sample \\
\hline 8 & $\begin{array}{l}\text { Volatility Timing strategy of Kirby and Ostdiek(2012). Use the } \\
\text { the shrinkage covariance matrix of Ledoit and Wolf(2004) and a } \\
\text { tuning parameter of } 2 \text {. }\end{array}$ & VT \\
\hline
\end{tabular}

The table lists the portfolio strategies that are used in the study. The first two strategies are based on the characteristic portfolio approach of Brandt et al(2009). The next two strategies are the passive benchmarks and the final four strategies are the alternative mean-variance strategies. The final column contains the abbreviation used for each strategy. 
Table 2 Summary Statistics

\begin{tabular}{lrrr}
\hline & Mean & Median & Std Deviation \\
Size & 13.009 & 12.731 & 1.683 \\
BM & 0.436 & 0.381 & 0.273 \\
Momentum & 15.14 & 10.558 & 41.721 \\
Return & 1.019 & 0.591 & 9.822 \\
\hline
\end{tabular}

The table reports summary statistics of the characteristics and excess returns for the individual stocks of the largest 350 companies that meet the criteria for inclusion each month between July 1991 and December 2012. The summary statistics include the time-series averages of the cross-sectional mean, median, and standard deviation of the characteristic values at the start of each evaluation month and the evaluation month excess returns. The momentum characteristic and returns are in $\%$ terms and the size and $(1+\mathrm{BM})$ characteristics are in logs. 
Table 3 Performance of the Brandt et al(2009) Portfolio Strategies

\begin{tabular}{|c|c|c|c|c|c|c|c|}
\hline \multicolumn{8}{|c|}{ Panel A: Performance } \\
\hline & Mean & $\sigma$ & Sharpe & CER & $\Delta$ & & \\
\hline $1 / \mathrm{N}$ & 0.573 & 4.877 & 0.118 & -0.022 & & & \\
\hline VW & 0.324 & 4.132 & 0.078 & -0.103 & & & \\
\hline Char & 4.079 & 13.94 & 0.293 & -0.779 & -1.691 & & \\
\hline Char $_{50}$ & 3.111 & 11.698 & 0.266 & -0.31 & -0.713 & & \\
\hline Char $_{10}$ & 3.887 & 13.474 & 0.288 & -0.652 & -1.428 & & \\
\hline CharSS & 1.044 & 5.437 & 0.192 & 0.305 & $0.319^{1}$ & & \\
\hline \multicolumn{8}{|c|}{ Panel B: $z$-test of Equal Sharpe Performance } \\
\hline & $1 / \mathrm{N}$ & VW & Char & Char $_{50}$ & Char $_{10}$ & & \\
\hline VW & -1.08 & & & & & & \\
\hline Char & $2.12^{1}$ & $2.56^{1}$ & & & & & \\
\hline Char $_{50}$ & $1.96^{1}$ & $2.35^{1}$ & $-2.11^{1}$ & & & & \\
\hline Char $_{10}$ & $2.1^{1}$ & $2.54^{1}$ & $-1.86^{2}$ & $2.16^{1}$ & & & \\
\hline CharSS & $2.48^{1}$ & $2.24^{1}$ & -1.56 & -1.32 & -1.53 & & \\
\hline \multicolumn{8}{|c|}{ Panel C: $z$-test of Equal CER Performance } \\
\hline & $1 / \mathrm{N}$ & VW & Char & Char $_{50}$ & Char $_{10}$ & & \\
\hline VW & -0.44 & & & & & & \\
\hline Char & -0.65 & -0.57 & & & & & \\
\hline Char $_{50}$ & -0.33 & -0.22 & 1.34 & & & & \\
\hline Char $_{10}$ & -0.57 & -0.48 & $1.71^{2}$ & -1.24 & & & \\
\hline CharSS & $1.99^{1}$ & 1.45 & 1.01 & 0.8 & 0.95 & & \\
\hline \multicolumn{8}{|c|}{ Panel D: Summary Statistics of Optimal Weights and Turnover } \\
\hline & $|x|$ & $\operatorname{Min} \mathrm{x}$ & Max $x$ & $\operatorname{Sum}(x<0)$ & $\operatorname{Prop}(x<0)$ & $\operatorname{Prop}(x>0)$ & Turnover \\
\hline $1 / \mathrm{N}$ & 0.286 & 0.286 & 0.286 & 0 & 0 & 100 & 0.098 \\
\hline VW & 0.286 & 0.006 & 8.408 & 0 & 0 & 100 & 0.021 \\
\hline Char & 2.329 & -6.946 & 18.245 & -357.501 & 51.094 & 48.906 & 3.414 \\
\hline Char $_{50}$ & 1.835 & -5.188 & 13.924 & -271.169 & 50.052 & 49.948 & 2.55 \\
\hline Char $_{10}$ & 2.227 & -6.581 & 17.366 & -339.792 & 50.965 & 49.035 & 3.236 \\
\hline CharSS & 0.286 & 0 & 3.995 & 0 & 0 & 48.42 & 0.422 \\
\hline
\end{tabular}

${ }^{1}$ Significant at 5\%

${ }^{2}$ Significant at $10 \%$ 
The table reports the after-cost out-of-sample performance of six portfolio strategies between July 1991 and December 2012. The investment universe is the largest 350 U.K. stocks that meet the criteria for inclusion each month. The six strategies are estimated each month using a rolling estimation window of 120 months. I set $\gamma=5$ for the Char, Char 50 , Char ${ }_{10}$, and CharSS strategies. The Char, Char ${ }_{50}$, $\mathrm{Char}_{10}$, and CharSS strategies use the size, BM, and momentum stock characteristics. The performance of the strategies is adjusted for the effects of trading costs assuming a level of proportional costs per transaction of 50 basis points. Panel A of the table reports the performance of the six strategies. The panel includes the mean and standard deviation of monthly excess returns (\%), the Sharpe(1966) measure, CER measure $(\%)$, and performance fee $(\Delta, \%)$. The CER measure and performance fee assumes $\gamma=5$. Panels B and C report the $z$-test of equal Sharpe (panel B) and CER (panel C) performance between the different strategies. Panel D reports summary statistics of the optimal weights and the average turnover of the six strategies. The summary statistics of the optimal weights include the time-series averages (\%) of the mean absolute weight $(|x|)$, minimum weight $(\operatorname{Min} x)$, maximum weight $(\operatorname{Max} x)$, sum of the short positions $(\operatorname{Sum}(x<0)$ ), the proportion of negative weights $(\operatorname{Prop}(\mathrm{x}<0))$, and the proportion of positive weights $(\operatorname{Prop}(\mathrm{x}>0))$. The test statistics are corrected for the effects of heteroskedasticity and serial correlation using the automatic lag selection (without prewhitening) of Newey and West(1994). 
Table 4 Performance of Alternative Mean-Variance Strategies

\begin{tabular}{|c|c|c|c|c|c|c|c|}
\hline \multicolumn{8}{|c|}{ Panel A: Performance } \\
\hline & Mean & $\sigma$ & Sharpe & CER & $\Delta$ & & \\
\hline MVChar & 1.768 & 13.423 & 0.132 & -2.737 & -3.482 & & \\
\hline GMV & 0.07 & 3.077 & 0.023 & -0.167 & -0.134 & & \\
\hline Sample & 0.359 & 6.353 & 0.057 & -0.65 & -0.657 & & \\
\hline VT & 0.545 & 4.158 & 0.131 & 0.112 & $0.141^{1}$ & & \\
\hline \multicolumn{8}{|c|}{ Panel B: $z$-test of Equal Sharpe Performance } \\
\hline & $1 / \mathrm{N}$ & VW & Char & CharSS & MVChar & GMV & Sample \\
\hline MVChar & 0.24 & 0.99 & $-2.8^{1}$ & -1.17 & & & \\
\hline GMV & -1.4 & -0.98 & $-2.91^{1}$ & $-2.37^{1}$ & -1.57 & & \\
\hline Sample & -1.02 & -0.38 & $-2.57^{1}$ & $-2.32^{1}$ & -1.32 & 0.44 & \\
\hline $\mathrm{VT}^{\mathrm{I}}$ & 1.03 & 1.52 & $-1.9^{2}$ & -1.63 & -0.01 & $1.73^{2}$ & 1.15 \\
\hline \multicolumn{8}{|c|}{ Panel C: $z$-test of Equal CER Performance } \\
\hline & $1 / \mathrm{N}$ & VW & Char & CharSS & MVChar & GMV & Sample \\
\hline MVChar & -1.21 & -1.19 & -0.9 & -1.38 & & & \\
\hline GMV & -0.48 & -0.29 & 0.52 & -1.36 & 1.2 & & \\
\hline Sample & $-1.99^{1}$ & -1.54 & 0.1 & $-2.83^{1}$ & 0.94 & -1.13 & \\
\hline VT & $1.71^{2}$ & 1.48 & 0.77 & -0.95 & 1.28 & 1.12 & $2.26^{1}$ \\
\hline \multicolumn{8}{|c|}{ Panel D: Summary Statistics of Optimal Weights and Turnover } \\
\hline & $|x|$ & $\operatorname{Min} \mathrm{x}$ & $\operatorname{Max} x$ & $\operatorname{Sum}(x<0)$ & $\operatorname{Prop}(\mathrm{x}<0)$ & $\operatorname{Prop}(x>0)$ & Turnover \\
\hline MVChar & 0.286 & 0 & 29.875 & 0 & 0 & 51.601 & 0.747 \\
\hline GMV & 0.874 & -2.989 & 4.35 & -102.863 & 39.152 & 60.848 & 0.697 \\
\hline Sample & 0.286 & 0 & 21.324 & 0 & 0 & 49.754 & 0.296 \\
\hline VT & 0.286 & 0.004 & 1.581 & 0 & 0 & 100 & 0.084 \\
\hline
\end{tabular}

${ }^{1}$ Significant at 5\%

${ }^{2}$ Significant at $10 \%$

The table reports the after-cost out-of-sample performance of four alternative mean-variance portfolio strategies between July 1991 and December 2012. The investment universe is the largest 350 U.K. stocks that meet the criteria for inclusion each month. The four strategies are estimated each month using a rolling estimation window of 120 months. I set $\gamma=5$ for the MVChar and Sample strategies, and the tuning parameter=2 for the VT strategy. The performance of the strategies is adjusted for the effects of trading costs assuming a level of proportional costs per transaction of 50 basis points. Panel A of the table reports the performance of the four strategies. The panel includes the mean and standard deviation of monthly excess returns (\%), the Sharpe(1966) measure, CER measure (\%), and performance fee $(\Delta, \%)$. The CER measure and performance fee assumes $\gamma=5$. Panels B and $\mathrm{C}$ report the $z$-test of equal Sharpe (panel B) and CER (panel C) performance between the different strategies and the $1 / \mathrm{N}, \mathrm{VW}$, Char, and CharSS strategies. Panel D reports summary statistics of the optimal weights and the average turnover of the four strategies. The summary statistics of the optimal weights include the time-series averages $(\%)$ of the mean absolute weight $(|x|)$, minimum weight $(\operatorname{Min} x)$, maximum weight $(\operatorname{Max} x)$, sum of the short positions $(\operatorname{Sum}(x<0)$ ), the proportion of negative weights $(\operatorname{Prop}(\mathrm{x}<0))$, and the proportion of positive weights $(\operatorname{Prop}(\mathrm{x}>0))$. The test statistics are corrected for the effects of heteroskedasticity and serial correlation using the automatic lag selection (without prewhitening) of Newey and West(1994). 
Table 5 Performance of Portfolio Strategies: Subperiod Evidence

\begin{tabular}{lccccr}
\hline \multicolumn{6}{l}{ Panel A: Performance of Strategies between July 1991 and December 2006 } \\
1/N & Mean & $\sigma$ & Sharpe & CER & $\Delta$ \\
VW & 0.485 & 4.409 & 0.11 & -0.001 & \\
Char & 0.405 & 3.989 & 0.101 & 0.007 & -1.674 \\
CharSS & 5.223 & 14.901 & 0.35 & -0.328 & $0.475^{2}$ \\
MVChar & 1.118 & 5.048 & 0.221 & 0.481 & -0.305 \\
GMV & 1.739 & 8.739 & 0.199 & -0.17 & -0.326 \\
Sample & -0.106 & 3.059 & -0.035 & -0.339 & -0.67 \\
VT & 0.659 & 7.132 & 0.092 & -0.612 & 0.081 \\
\hline Panel B: Performance of Strategies between January 2007 and December 2012 & \\
& 0.439 & 3.813 & 0.115 & CER & $\Delta$ \\
1/N & Mean & $\sigma$ & Sharpe & -0.042 & \\
VW & 0.661 & 5.303 & 0.125 & -0.213 & -1.706 \\
Char & 0.243 & 4.268 & 0.057 & -1.165 & 0.165 \\
CharSS & 2.935 & 12.806 & 0.229 & 0.13 & -7.522 \\
MVChar & 0.971 & 5.8 & 0.167 & -5.303 & -0.058 \\
GMV & 1.797 & 16.852 & 0.107 & 0.007 & $0.1999^{1}$ \\
Sample & 0.245 & 3.085 & 0.079 & -0.683 & \\
VT & 0.059 & 5.447 & 0.011 & 0.15 & \\
\hline
\end{tabular}

${ }^{1}$ Significant at $5 \%$

${ }^{2}$ Significant at $10 \%$

The table reports the after-cost out-of-sample performance of eight portfolio strategies between July 1991 and Decmber 2006 (panel A) and January 2007 and December 2012 (panel B). The investment universe is the largest 350 U.K. stocks that meet the criteria for inclusion each month. The eight strategies are estimated at the start of each month using a rolling estimation window of 120 months. I set $\gamma=5$ for the Char, CharSS, MVChar and Sample strategies and a tuning parameter $=2$ for the VT strategy. The performance of the strategies is adjusted for the effects of trading costs assuming a level of proportional costs per transaction of 50 basis points. The table includes the mean and standard deviation of monthly excess returns (\%), the Sharpe(1966) measure, CER measure (\%), and performance fee $(\Delta, \%)$. The CER measure and performance fee assume $\gamma=5$. The test statistics are corrected for the effects of heteroskedasticity and serial correlation using the automatic lag selection (without prewhitening) of Newey and West(1994). 
Table 6 Performance and Number of Stocks in Optimal Portfolios

\begin{tabular}{|c|c|c|c|c|c|}
\hline \multicolumn{6}{|c|}{ Panel A: Performance of Strategies when $\mathrm{N}=50$} \\
\hline & Mean & $\sigma$ & Sharpe & CER & $\Delta$ \\
\hline $1 / \mathrm{N}$ & 0.401 & 4.325 & 0.093 & -0.067 & \\
\hline VW & 0.289 & 4.122 & 0.07 & -0.136 & \\
\hline Char & 0.988 & 8.433 & 0.117 & -0.789 & -0.822 \\
\hline CharSS & 0.479 & 4.578 & 0.105 & -0.045 & 0.02 \\
\hline MVChar & 0.277 & 4.743 & 0.058 & -0.285 & -0.225 \\
\hline GMV & 0.221 & 3.87 & 0.057 & -0.154 & -0.085 \\
\hline Sample & 0.143 & 6.005 & 0.024 & -0.759 & -0.711 \\
\hline VT & 0.43 & 3.773 & 0.114 & 0.074 & $0.144^{1}$ \\
\hline \multicolumn{6}{|c|}{ Panel B: Performance of Strategies when $\mathrm{N}=100$} \\
\hline & Mean & $\sigma$ & Sharpe & CER & $\Delta$ \\
\hline $1 / \mathrm{N}$ & 0.459 & 4.581 & 0.1 & -0.066 & \\
\hline VW & 0.307 & 4.133 & 0.074 & -0.12 & \\
\hline Char & 1.307 & 9.702 & 0.135 & -1.046 & -1.173 \\
\hline CharSS & 0.55 & 4.932 & 0.112 & -0.058 & 0.003 \\
\hline MVChar & 0.475 & 5.708 & 0.083 & -0.339 & -0.291 \\
\hline GMV & 0.063 & 3.847 & 0.016 & -0.307 & -0.236 \\
\hline Sample & 0.351 & 6.382 & 0.055 & -0.667 & -0.631 \\
\hline VT & 0.463 & 3.93 & 0.118 & 0.077 & $0.147^{1}$ \\
\hline \multicolumn{6}{|c|}{ Panel C: Performance of Strategies when $\mathrm{N}=200$} \\
\hline & Mean & $\sigma$ & Sharpe & CER & $\Delta$ \\
\hline $1 / \mathrm{N}$ & 0.538 & 4.918 & 0.109 & -0.067 & \\
\hline VW & 0.321 & 4.147 & 0.077 & -0.109 & \\
\hline Char & 2.135 & 11.76 & 0.182 & -1.322 & -1.684 \\
\hline CharSS & 0.749 & 5.54 & 0.135 & -0.018 & 0.039 \\
\hline MVChar & 0.775 & 7.444 & 0.104 & -0.611 & -0.605 \\
\hline GMV & -0.199 & 3.586 & -0.055 & -0.52 & -0.442 \\
\hline Sample & 0.599 & 6.295 & 0.095 & -0.392 & -0.352 \\
\hline VT & 0.499 & 4.197 & 0.119 & 0.058 & $0.131^{2}$ \\
\hline
\end{tabular}

${ }^{1}$ Significant at 5\%

${ }^{2}$ Significant at $10 \%$

The table reports the after-cost out-of-sample performance of eight portfolio strategies between July 1991 and December 2012 of randomly selected portfolios each month of 50 stocks (panel A), 100 stocks (panel B), and 200 stocks (panel C) among the largest 350 U.K. stocks that meet the criteria for inclusion. The eight strategies are estimated at the start of each month using a rolling estimation window of 120 months. I set $\gamma=5$ for the Char, CharSS, MVChar and Sample strategies and the tuning parameter=2 for the VT strategy. The performance of the strategies is adjusted for the effects of trading costs assuming a level of proportional costs per transaction of 50 basis points. The table includes the mean and standard deviation of monthly excess returns (\%), the Sharpe(1966) measure, CER measure $(\%)$, and performance fee $(\Delta, \%)$. The CER measure and performance fee assumes $\gamma=5$. The test statistics are corrected for the effects of heteroskedasticity and serial correlation using the automatic lag selection (without prewhitening) of Newey and West(1994). 


\section{References}

Ait-Sahalia, Y. and M.W. Brandt, 2001, Variable selection for portfolio choice, Journal of Finance, 56, 1297-1351.

Banz, R.W., 1981, The relationship between return and market value of common stocks, Journal of Financial Economics, 9, 3-18.

Board, J.L.G. and C.M.S. Sutcliffe, 1994, Estimation methods in portfolio selection and the effectiveness of short sales restrictions: U.K. evidence, Management Science, 40, 516-534.

Brandt, M.W., 1999, Estimating portfolio and consumption choice: A conditional Euler equations approach, Journal of Finance, 54, 1609-1646.

Brandt, M.W. and P. Santa-Clara, 2006, Dynamic portfolio selection by augmenting the asset space, Journal of Finance, 61, 2187-2217.

Brandt, M.W., Santa-Clara, P. and R. Valkanov, 2009, Parametric portfolio policies: Exploiting characteristics in the cross-section of equity returns, Review of Financial Studies, 22, 3411-3447.

Carhart, M. M., 1997. Persistence in mutual fund performance. Journal of Finance, 52, 57-82.

Chordia, T., Subrahmanyam, A. and Q. Tong, 2014, Have capital market anomalies attenuated in the recent era of high liquidity and trading activity, Journal of Accounting and Economics, 58, 41-58.

Cochrane, J.H., 2011, Discount rates, Journal of Finance, 66, 1047-1108.

DeMiguel, V., Garlappi, L. and R. Uppal, 2009, Optimal versus naïve diversification: How inefficient is the 1/N portfolio strategy?, Review of Financial Studies, 22, 1915-1953.

DeMiguel, V, Plyakha, Y., Uppal, R. and G. Vilkov, 2013a, Improving portfolio selection using option-implied volatility and skewness, Journal of Financial and Quantitative Analysis, $48,1813-1845$. 
DeMiguel, V., Martin-Utrera, A., F.J. Nogales, 2013b, Size matters: Optimal calibration of shrinkage estimators for portfolio selection, Journal of Banking and Finance, 37, 3018-3034. Dimson, E., Nagel, S. and G. Quigley, 2003, Capturing the value premium in the U.K. 19552001, Financial Analysts Journal 59, 35-45.

Fama, E.F. and K.R. French, 1992, The cross-section of expected stock returns, 47, 427-465.

Fama, E.F. and K.R. French, 2008, Dissecting anomalies, Journal of Finance, 63, 1653-1678. Fama, E.F. and J. MacBeth, 1973, Risk, return, and equilibrium: Empirical tests, Journal of Political Economy, 81, 607-636.

Fleming, J., Kirby, C. and B. Ostdiek, 2001, The economic value of volatility timing, Journal of Finance, 56, 329-352.

Fleming, J., Kirby, C. and B. Ostdiek, 2003, The economic value of volatility timing using “realized" volatility, Journal of Financial Economics, 67, 473-509.

Fletcher, J., 2009, Risk reduction and mean-variance analysis: An empirical investigation, Journal of Business Finance and Accounting, 36, 951-971.

Fletcher, J., 2011, Do optimal diversification strategies outperform the 1/N strategy in U.K. stock returns, International Review of Financial Analysis, 20, 375-385.

Goyal, A., 2012, Empirical cross-sectional asset pricing: A survey, Financial Markets and Portfolio Management, 26, 3-38.

Green, J., Hand J.R.M. and X.F. Zhang, 2014, The remarkable multidimensionality in the cross section of expected US stock returns, Working Paper, Pennsylvania State University.

Gregory, A., Tharyan, R. and A. Christidis, 2013, Constructing and testing alternative versions of the Fama-French and Carhart models in the UK, Journal of Business Finance and Accounting, 40, 172-214.

Hansen, L.P., 1982, Large sample properties of generalized method of moments estimators, Econometrica, 50, 1029-1053. 
Harvey, C.R., Liu, Y. and H. Zhu, 2015, ... and the cross-section of expected returns, Working Paper, Duke University.

Haugen, R.A. and N. Baker, 1996, Commonality in the determinants of expected stock returns, Journal of Financial Economics, 41, 401-439.

Hjalmarsson, E. and P. Manchev, 2012, Characteristic-based mean-variance portfolio choice, Journal of Banking and Finance, 36, 1392-1401.

Jagannathan, R. and T. Ma, 2003, Risk reduction in large portfolios: Why imposing the wrong constraint helps, Journal of Finance, 58, 1651-1683.

Jegadeesh, N. and S. Titman, 1993, Returns to buying winners and selling losers: Implications for stock market efficiency, Journal of Finance, 48, 65-92.

Jobson, J.D. and B. Korkie, 1980, Estimation of markowitz efficient portfolios, Journal of American Statistical Association, 75, 544-554.

Jobson, J.D. and B. Korkie, 1981, Putting markowitz theory to work, Journal of Portfolio Management, 7, 70-74.

Kirby, C. and B. Ostdiek, 2012, It's all in the timing: Simple active portfolio strategies that outperform naïve diversification, Journal of Financial and Quantitative Analysis, 47, 437467.

Lamoureux, C. and H. Zhang, 2014, Risk, return, and the optimal exploitation of stock characteristics, Working Paper, University of Arizona.

Ledoit, O. and M. Wolf, 2004, A well-conditioned estimator for large-dimensional covariance matrices, Journal of Multivariate Analysis, 88, 365-411.

Ledoit, O. and M. Wolf, 2008, Robust performance hypothesis testing with the Sharpe ratio, Journal of Empirical Finance, 15, 850-859.

Ledoit, O. and M. Wolf, 2014, Nonlinear shrinkage of the covariance matrix for portfolio selection: Markowitz meets Goldilocks, Working Paper, University of Zurich. 
Lewellen, J.W., 2014, The cross section of expected stock returns, Critical Finance Review, forthcoming.

Liu, W. and N. Strong, 2008, Biases in decomposing holding period portfolio returns, Review of Financial Studies, 21, 2243-2274.

McLean, R.D. and J. Pontiff, 2015, Does academic research destroy stock return predictability, Working Paper, University of Alberta.

Michaud, R.O., 1989, The Markowitz optimization enigma: Is "optimized" optimal?, Financial Analysts Journal, 45, 31-42.

Nagel, S., 2013, Empirical cross-sectional asset pricing, Annual Review of Financial Economics, $5,167-199$

Newey, W.K. and K.D. West, 1994, Automatic lag selection in covariance matrix estimation, Review of Economic Studies, 61, 631-653.

Plazzi, A, Torous, W. and R. Valkanov, 2011, Exploiting property characteristics in commercial real estate portfolio allocation, Journal of Portfolio Management, 35, 39-50.

Sharpe, W.F., 1966, Mutual fund performance, Journal of Business 39, 119-138.

Shumway, Tyler, 1997, The delisting bias in CRSP data, Journal of Finance 52, 327-340.

Subrahmanyam, A., 2010, The cross-section of expected stock returns: What have we learnt from the past twenty-five years of research?,European Financial Management, 16, 27-42.

Zhang, H., 2012a, Active allocation among a large set of stocks: How effective is the parametric rule?, Working Paper, University of Arizona.

Zhang, H., 2012b, On the economic significance of stock return predictability: Evidence from macroeconomic state variables, Working Paper, University of Arizona. 